\title{
Anti-arrhythmic and cardio-protective effects of atorvastatin and a potent pyridoindole derivative on isolated hearts from rats with metabolic syndrome
}

\author{
Liptak B ${ }^{1,2}$, Knezl V ${ }^{1}$, Gasparova $Z^{1}$ \\ Institute of Experimental Pharmacology and Toxicology, Centre of Experimental Medicine, Slovak \\ Academy of Sciences, Bratislava, Slovakia. liptaq.b@gmail.com
}

\begin{abstract}
OBJECTIVES: Aims of this study were to investigate the anti-arrhythmic and cardio-protective effect of atorvastatin and of a new pyridoindole derivative (SMe1EC2) on isolated and perfused hearts while following the Langendorff principles.

BACKGROUND: Metabolic syndrome is a widely distributed condition progressing to cardiovascular disease. Many of the metabolic syndrome patients take (HMG)-co-enzyme $\mathrm{A}(\mathrm{CoA})$ reductase inhibitors with potential cardioprotective effects. SMe1EC2 is a promising new drug, exerting many positive effects in experimental settings. METHODS: Rats with induced metabolic syndrome were treated with atorvastatin $(25 \mathrm{mg} / \mathrm{kg})$ and SMe1EC2 ( $25 \mathrm{mg} / \mathrm{kg}$ and $0.5 \mathrm{mg} / \mathrm{kg}$, respectively) daily for 3 weeks. After the treatment, the hearts were isolated and perfused according to Langendorff.

RESULTS: Both atorvastatin and SMe1EC2 improved cardiac function by elevating the left ventricular developed pressure (VLDP) and cardiac contractility. Both SMe1EC2-treated groups improved LVDP during reperfusion, significantly increased $-\mathrm{dP} / \mathrm{dt}$, and moderately elevated $+\mathrm{dP} / \mathrm{dt}$ values. The treatment with both atorvastatin and SMe1EC2 $(25 \mathrm{mg} / \mathrm{kg})$ significantly reduced malignant arrhythmia in comparison to control group and group treated with SMe1EC2 $0.5 \mathrm{mg} / \mathrm{kg}$.

CONCLUSIONS: Owing to its anti-arrhythmic and cardio-protective effects, atorvastatin and SMe1EC2 could be of benefit to patients suffering from metabolic syndrome (Tab. 3, Fig. 3, Ref. 41). Text in PDF www.elis.sk. KEY WORDS: hyper-triacylglycerolemic rats, Langendorff, ventricular fibrillation, dyslipidemia.
\end{abstract}

\section{Introduction}

Atherosclerosis is an underlying cause of about $50 \%$ of all deaths in westernized societies (1) while the subjects with potential atherosclerosis and cardiovascular disease are in many cases individuals with metabolic syndrome diagnosis. These patients have chronic elevation of triacylglycerols (TG), low-density lipoprotein cholesterol (LDL), very low-density lipoprotein cholesterol (VLDL), decreased high-density lipoprotein cholesterol (HDL), and impaired glucose metabolism. They are often overweight as a result of factors commonly linked to unhealthy lifestyle and diet, which is characteristic for a significant part of the population today

${ }^{1}$ Institute of Experimental Pharmacology and Toxicology, Centre of Experimental Medicine, Slovak Academy of Sciences, Bratislava, Slovakia, and ${ }^{2}$ Department of Pharmacology, Jessenius Faculty of Medicine, Comenius University in Bratislava, BioMed, Martin, Slovakia

Address for correspondence: B. Lipták, Institute of Experimental Pharmacology and Toxicology, Centre of Experimental Medicine, Slovak Academy of Sciences, Dúbravská cesta 9, SK-841 04 Bratislava, Slovakia. Phone: +421.944 .837494$

Acknowledgements: This study was financially supported by the VEGA grant No. 2/0054/15 and VEGA grant No. 2/0120/19.
$(2,3,4,5)$. Negative lifestyle adaptations are irrefutably linked to the emergence of atherosclerosis and lead to major cardiovascular disease, complications and possible death $(6,7,8,9)$. The major cause of cardiovascular mortality is that of malign heart arrhythmias. They represent a major clinical problem while its management is unsatisfactory $(10,11)$. Ventricular and atrial arrhythmias may result in severe morbidity, coma and eventual death. More than half of the patients with ischemic heart disease die due to ventricular arrhythmias and ventricular tachyarrhythmias, which are the most common and most severe forms of heart dysrhythmias occurring in $84 \%$ of patients with sudden cardiac death (12).

Patients suffering from metabolic syndrome, type II diabetes mellitus, and obesity may have decreased chances of survival at the onset of ventricular arrhythmia. In these patients, malign heart arrhythmias may occur more frequently and with increased duration, severity and eventual damage. The incidence of coronary heart disease is increased threefold in patients with metabolic syndrome with markedly increased cardiovascular morbidity (13). Metabolic syndrome has been identified in $\sim 35 \%$ of patients in the USA (14) and ranges from $8 \%$ to $43 \%$ in men and $7 \%$ to $56 \%$ in women across the world $(15,16)$. Dyslipidemia occurs in $52.9 \%$ of adults in the USA (17) and $53.6 \%$ in China (18). Elevated total cholesterol concentrations $(\geq 190 \mathrm{mg} / \mathrm{dL}$ ) were found in $60.5 \%$ of 
women and $56.6 \%$ of men in the German population (19). Metabolic syndrome is a global health problem concerning patients across many countries of western and eastern parts of the world.

Many of these patients receive treatment with drugs inhibiting the cholesterol synthesis, such as statins. Atorvastatin is a widely used 3-hydroxy-3-methylglutaryl (HMG)-co-enzyme A $(\mathrm{CoA})$ reductase inhibitor taken by many patients in the effort to reduce progression of atherosclerosis (20). Besides the reduction of LDL cholesterol, statins have other effects. It has been suggested that these effects may provide cardiovascular protection, be of benefit at the onset of myocardial infarction, as well as decrease ischemic-reperfusion injury (21). Atorvastatin is thought to provide anti-arrhythmic protection and may reduce mortality $(22,23)$ by restoring optimal heart functions $(24)$. Then a novel experimental drug SMe1EC2 was identified to exert many beneficial effects expressing potent anti-arrhythmic activity $(25,26)$ with unknown action. The anti-arrhythmic activity of SMe1EC2 was here re-evaluated on a matabolic syndrome rat model to obtain additional results regarding this potential drug.

Our hypotheses were as follows: 1) Metabolic disturbances associated in the metabolic syndrome will result in an increase in the occurrence of malign heart arrhythmias in comparison to treated animals; 2) Administration of atorvastatin and potent experimental drug SMe1EC2 will protect these animals from malign heart arrhythmias and decrease cardiac abnormalities after global ischemia.

\section{Material and methods}

\section{Animals and animal model}

All procedures involving animals were performed in compliance with the Principles of Laboratory Animal Care issued by the Ethical Committee of the Institute of Experimental Pharmacology and Toxicology and State Veterinary and Food Administration of Slovakia. Prague hereditary HTG rats $(n=40)$ were obtained from the breeding station Dobra Voda (Slovak Republic, reg. No. SK CH 24016). The animals were divided into four groups (ten animals per group). The laboratory rats were than divided into boxes, each box containing five animals. After a one-week quarantine, all the animals were kept in a housing room for 8 subsequent weeks. All rats in all four groups received high-fat, high-fructose diet (HFFD; 7.5 $\%$ lard, $1 \%$ cholesterol and $10 \%$ fructose). All animals received the same diet for 8 weeks. After 5 weeks of diet, one group (HFFDA) received $25 \mathrm{mg} / \mathrm{kg}$ of atorvastatin, another group (HFFD$\mathrm{SMe} 25$ ) received $25 \mathrm{mg} / \mathrm{kg}$ of experimental pyridoindole derivative SMe1EC2, and the third group (HFFD-SMe0.5) received the latter drug but in a different dosage $(0.5 \mathrm{mg} / \mathrm{kg})$. The control group (HFFD-C) received physiological solution. The application of substances was oral with a gastrointestinal probe. The substances were applied daily in the morning for a period of 21 days (3 weeks). The same researchers conducted all the applications. At this point of time, the animals were housed in standardized conditions with 12/12-h light/dark cycle and at 40-60\% humidity, with chow and water ad libitum. In the first, fifth and eighth weeks of the diet, weight, arterial blood pressure and fasting blood glucose were assessed. Blood samples were taken from all the animals. After 5 weeks of the diet, all the animals developed metabolic syndrome assessed by means of elevated total cholesterol, LDL cholesterol, triacylglycerol level, glucose and atrial pressure (not published), and decreased HDL cholesterol (27).

\section{Langendorff apparatus and experimental setting}

The hearts of all laboratory rats were isolated according to Langendorff principles. After the animals had been transported into the laboratory, they were anesthetized with diethyl ether and immediately decapitated (to isolate the brain). The heart was then rapidly isolated and cannulated in situ. The same researcher conducted all the procedures. After successful cannulation and initiation of the perfusion, all hearts were put immediately on the Langendorff apparatus for retrograde perfusion. The apparatus was set to constant pressure $(80 \mathrm{~mm} \mathrm{Hg})$. Krebs-Henseleit bicarbonate perfusion solution was prepared as follows (in $\mathrm{mM}$ ): $\mathrm{NaCl}$ (118), $\mathrm{KCl}$ (4.7), $\mathrm{CaCl}_{2}$ (2.5), $\mathrm{NaH}_{2} \mathrm{PO}_{4}$ (1.18), $\mathrm{NaHCO}_{3}$ (25), and glucose (11.1) equilibrated with a gas mixture of $95 \% \mathrm{O}_{2}$ and $5 \%$ $\mathrm{CO}_{2}$ at $37^{\circ} \mathrm{C}, \mathrm{pH}$ 7.4. Electrocardiograph electrodes were put on the right atrium and left ventricle of the heart and a latex balloon was inserted into the left ventricle immediately after placing the heart on the apparatus. After insertion of the latex balloon, the volume of the balloon was filled with water and the tubular balloon holder was connected to the pressure transducer via a tube. Left ventricular end-diastolic pressure (LVEDP) was set to give an approximate power of $0.5 \mathrm{kPa}(\sim 10 \mathrm{~mm} \mathrm{Hg})$ before starting the measurements. Tesla electro-manometers were used to monitor left ventricular pressure. The developed left ventricular pres-

Tab. 1. Baseline values of isolated hearts.

\begin{tabular}{lcccc}
\hline & HFFD-C & HFFD-A & HFFD-SMe25 & HFFD-SMe0.5 \\
\hline Heart rate (HR) (beats/min) & $280.1 \pm 22.3$ & $282.2 \pm 35.5$ & $259.1 \pm 6.8$ & $300.4 \pm 29.5^{* *}$ \\
Left ventricular developed pressure (LVDP) $(\mathrm{kPa})$ & $11.5 \pm 3.8$ & $14.9 \pm 3.0^{*}$ & $16.4 \pm 4.3^{* *}$ & $15.5 \pm 2.3^{*}$ \\
Left ventricular end-developed pressure (LVEDP) $(\mathrm{kPa})$ & $1.8 \pm 2.49$ & $0.9 \pm 0.8$ & $1.05 \pm 0.95$ & $0.8 \pm 0.8$ \\
Coronary flow $(\mathrm{ml} / \mathrm{min})$ & $15.1 \pm 6.0$ & $16.3 \pm 3.2$ & $16.9 \pm 7.3$ & $15.8 \pm 2.3$ \\
$-\mathrm{dP} / \mathrm{dt}(\mathrm{kPa} / \mathrm{s})$ & $207.4 \pm 73.4$ & $281.1 \pm 64.1^{*}$ & $285.5 \pm 62.0^{*}$ & $316.2 \pm 48.4^{* * *}$ \\
$+\mathrm{dP} / \mathrm{dt}(\mathrm{kPa} / \mathrm{s})$ & $286.8 \pm 109.2$ & $381.6 \pm 99.0^{*}$ & $417.9 \pm 108.8^{* *}$ & $420.7 \pm 67.5^{* *}$ \\
$-\mathrm{dP} / \mathrm{dt} / \mathrm{dP} / \mathrm{dt}$ & $0.73 \pm 0.05$ & $0.75 \pm 0.06$ & $0.69 \pm 0.07$ & $0.75 \pm 0.03^{*}$ \\
\hline
\end{tabular}

Values are presented as mean \pm SD. LVDP: HFFD-C vs HFFD-A ( $<<0.036)$, vs HFFD-SMe25 ( $<<0.0043)$, vs HFFD-SMe0.5 ( $<0.011)$. HR: HFFD-SMe25 vs HFFDSMe0.5 ( $<<0.009)$. $-d P / d t:$ HFFD-C vs HFFD-A ( $<00.015)$, vs HFFD-SMe25 $(\mathrm{p}<0.012)$, vs HFFD-SMe0.5 $(\mathrm{p}<0.0004)$. + dP/dt: HFFD-C vs HFFD-A ( $<0.04)$, vs HFFD-SMe25 ( $<<0.0073)$, vs HFFD-SMe0.5 ( $<<0.004)$. $-\mathrm{dP} / \mathrm{dt} /+\mathrm{dP} / \mathrm{dt}$ : HFFD-SMe25 vs HFFD-SMe $0.5(\mathrm{p}<0.028)$. 
Tab. 2. Baseline values of isolated hearts at the end of reperfusion after global ischemia.

\begin{tabular}{|c|c|c|c|c|}
\hline & HFFD-C & HFFD-A & HFFD-SMe25 & HFFD-SMe0.5 \\
\hline Heart rate (HR) (beats/min) & $268.9 \pm 59.6$ & $249.1 \pm 72.5$ & $274.0 \pm 45.5$ & $279.9 \pm 60.5$ \\
\hline Left ventricular developed pressure (LVDP) $(k P a)$ & $10.8 \pm 3.5$ & $11.9 \pm 3.3$ & $13.5 \pm 1.5$ & $13.9 \pm 2.1^{*}$ \\
\hline Left ventricular end-developed pressure $(\operatorname{LVEDP}(\mathrm{kPa})$ & $0.8 \pm 1.1$ & $1.0 \pm 1.1$ & $0.5 \pm 0.8$ & $0.2 \pm 0.4$ \\
\hline Coronary flow $(\mathrm{ml} / \mathrm{min})$ & $17.7 \pm 6.4$ & $14.6 \pm 3.8$ & $16.9 \pm 6.4$ & $13.6 \pm 2.4$ \\
\hline$-\mathrm{dP} / \mathrm{dt}(\mathrm{kPa} / \mathrm{s})$ & $215.8 \pm 72.7$ & $221.5 \pm 48.8$ & $249.1 \pm 83.3^{*}$ & $276.6 \pm 21.1^{*}$ \\
\hline$+\mathrm{dP} / \mathrm{dt}(\mathrm{kPa} / \mathrm{s})$ & $288.3 \pm 103.2$ & $317.1 \pm 90.8$ & $326.7 \pm 99.1$ & $378.5 \pm 44.8$ \\
\hline$-\mathrm{dP} / \mathrm{dt} /+\mathrm{dP} / \mathrm{dt}$ & $0.75 \pm 0.07$ & $0.71 \pm 0.08$ & $0.75 \pm 0.05$ & $0.73 \pm 0.03$ \\
\hline
\end{tabular}

Values are presented as mean \pm SD. LVDP: HFFD-C vs HFFD-SMe0.5 ( $<<0.036)$. $-\mathrm{dP} / \mathrm{dt}$ : HFFD-C vs HFFD-SMe25 ( $\mathrm{p}<0.041)$, vs HFFD-SMe0.5 (p $<0.042)$.

sure (LVDP), LVEDP, heart rate (HR), coronary flow (CF), $-\mathrm{dP} /$ $\mathrm{dt}$ and $+\mathrm{dP} / \mathrm{dt}$ were subsequently monitored with the BioLabF software throughout the experiment. After the setting, all hearts were kept stabilized for 15 minutes. Stabilization was followed by global ischemia lasting 20 minutes. The 20 -minute ischemia was followed by 20 -minute reperfusion. Then the stimulation electrodes were put on the myocardium and ascending stimulation followed with doses from $10 \mathrm{~mA}$ to $50 \mathrm{~mA}$. The goal was to induce sustained VF (lasting 2 minutes) or ventricular tachycardia (VT). If sustained VF or VT developed during the reperfusion and persisted until the end of the reperfusion, the hearts were not conducted to cardio-stimulation. After the induction of sustained VF or VT (2 min), CF was stopped and sinus rhythm recovery was monitored. During the reperfusion, the ventricular premature beats (VPB), ventricular tachycardia (VT) and ventricular fibrillation (VF) were monitored.

\section{Statistical analysis}

Analytic software from the BioLabF was used to analyze the data. STATISTICA 10 software was used for the statistics. ANO-
VA Fisher LSD test was used for data comparison. All data in tables is presented as mean $\pm \mathrm{SD}$. All data infigures and in the text is presented as mean $\pm \mathrm{SD}$. ${ }^{*} \mathrm{p}<0.05$, $* * \mathrm{p}<0.01, * * * \mathrm{p}<0.001$.

\section{Results}

LVDP, $-\mathrm{dP} / \mathrm{dt}$ and $+\mathrm{dP} / \mathrm{dt}$ values were significantly increased in all treated groups in comparison to the control HFFD-C group before global ischemia (Tab. 1).

LVDP was significantly higher in the HFFD-SMe 0.5 group in comparison to the HFFD-C group, while $-\mathrm{dP} / \mathrm{dt}$ was higher in both SMe1EC2 treatments in comparison to HFFD-C after global ischemia (Tab. 2). The LVDP course in the reperfusion is demonstrated in Figure 1. Both SMe1EC2 drug dosages elevated LVDP in crucial moments of reperfusion. A moderately higher value of developed ventricular pressure of both SMe1EC2 treatments was observed during the whole reperfusion period. The values of $-\mathrm{dP} / \mathrm{dt}$ were significantly elevated in the case of both dosages of SMe1EC2 drug treatment (Fig. 2). HR, CF, LVEDP, $+\mathrm{dP} / \mathrm{dt}$ and $-\mathrm{dP} / \mathrm{dt} /+\mathrm{dP} / \mathrm{dt}$ ratio did not differ significantly among

Left ventricular developed pressure (LVDP)

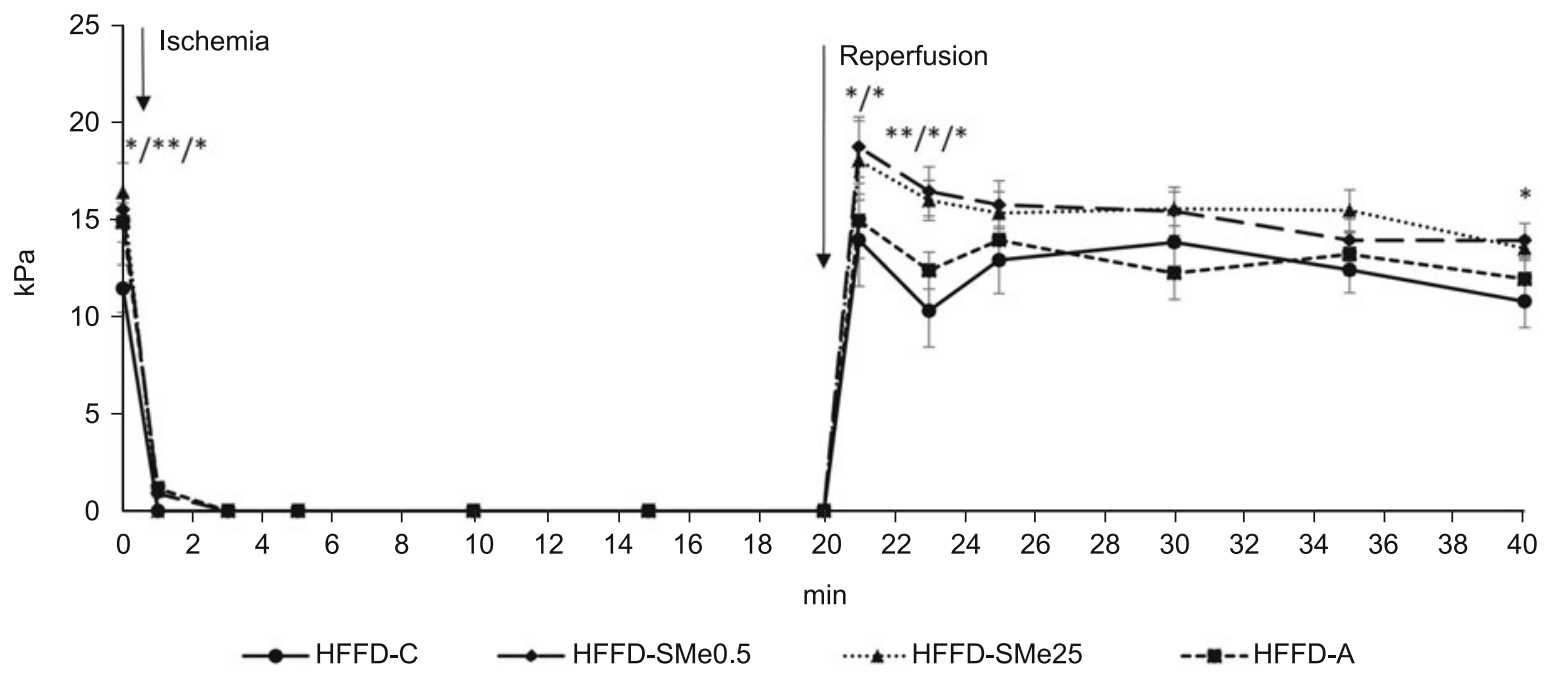

Fig. 1. LVDP during reperfusion. Values are presented as mean \pm SEM. 0 min stabilisation: HFFD-C vs HFFD-A (p $<0.036$ ), vs HFFD-SMe25 $(p<0.0043)$, vs HFFD-SMe0.5 ( $<<0.011), 1^{\text {st }}$ min reperfusion: HFFD-C vs HFFD-SMe0.5 ( $\left.<<0.025\right)$, HFFD-SMe0.5 vs HFFD-A (p < 0.037), $3^{\text {rd }}$ min reperfusion: HFFD-C vs HFFD-SMe0.5 $(p<0.004)$, vs HFFD-SMe25 $(p<0.036)$, HFFD-SMe0.5 vs HFFD-A $(p<0.016), 20^{\text {th }}$ min $^{2}$,perfusion: HFFD-C vs HFFD-SMe0.5 (p < 0.036). 


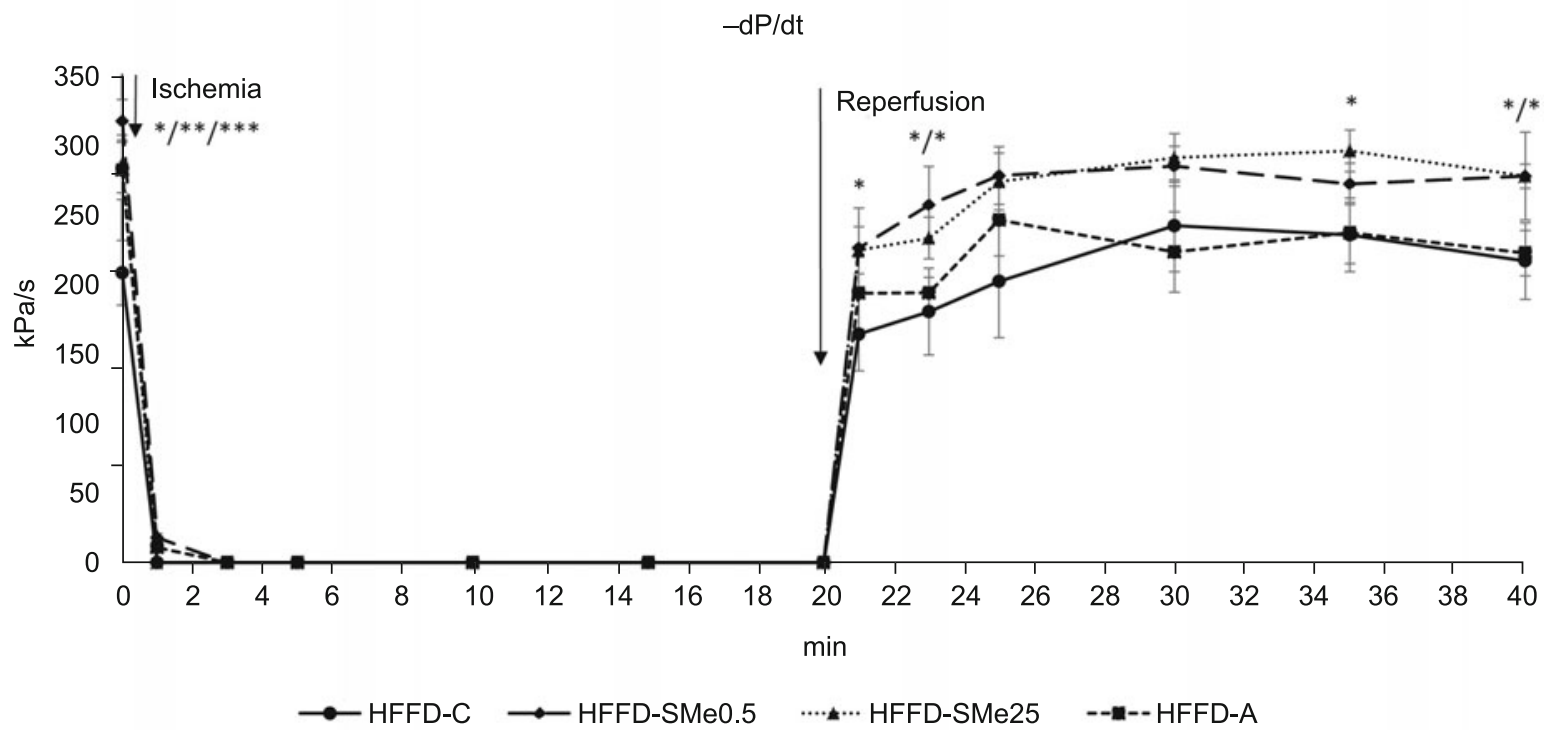

Fig. 2. - dP/dt during reperfusion. Values are presented as mean \pm SEM. 0 min stabilisation: HFFD-C vs HFFD-A (p<0.015), vs HFFD-SMe25 $(p<0.012)$, vs HFFD-SMe0.5 $(p<0.0004), 1^{\text {st }}$ min reperfusion: HFFD-C vs HFFD-SMe0.5 $(p<0.041), 3^{\text {rd }}$ min reperfusion: HFFD-C vs HFFDSMe0.5 ( $<<0.024)$, HFFD-SMe0.5 vs HFFD-A $(p<0.042), 15^{\text {th }}$ min reperfusion: HFFD-SMe25 vs HFFD-A $(p<0.041), 20^{\text {th }}$ min reperfusion: HFFD-C vs HFFD-SMe25 (p < 0.041), vs HFFD-SMe0.5 (p < 0.042).

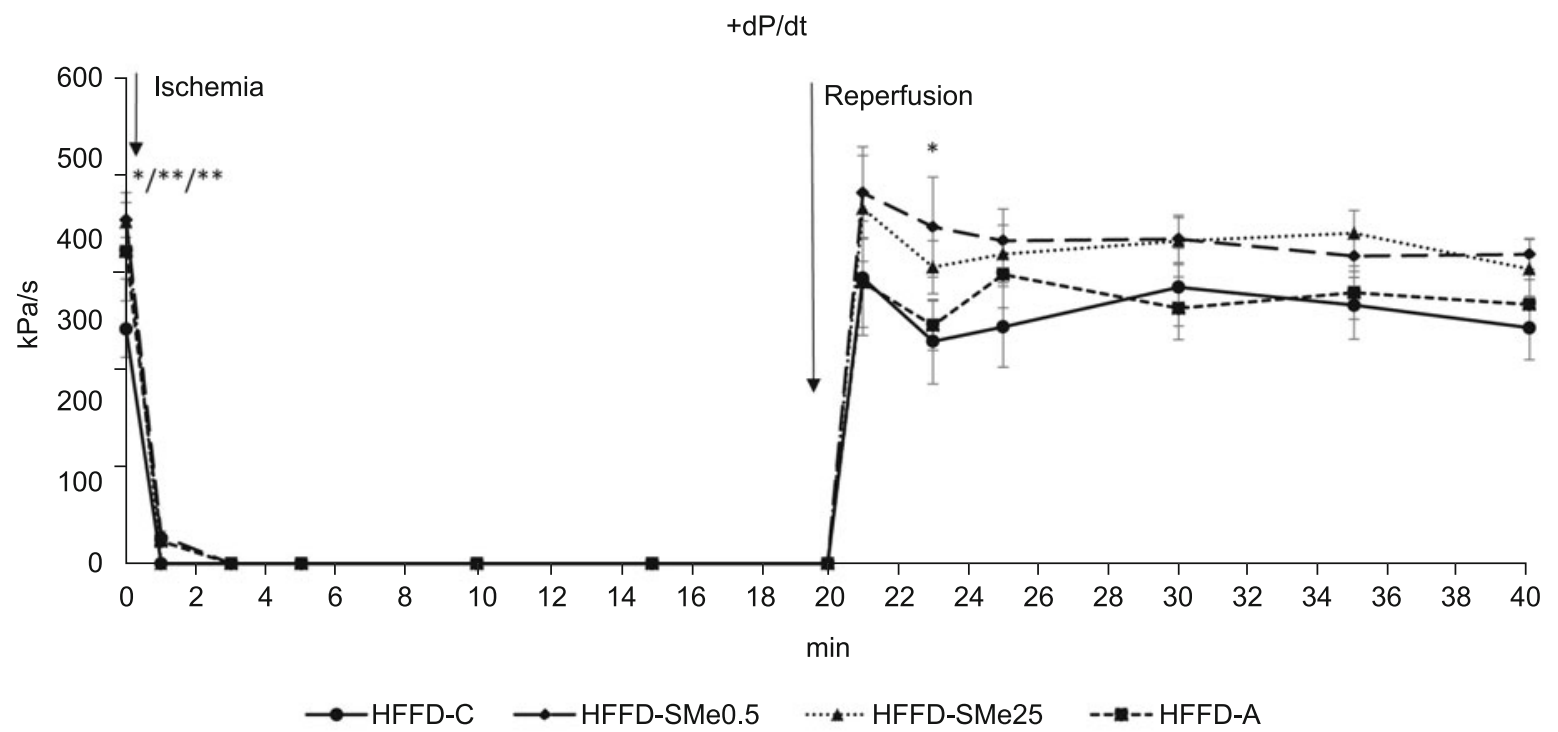

Fig. 3. + dP/dt during reperfusion. Values are presented as mean \pm SEM. 0 min stabilisation: HFFD-C vs HFFD-A (p $<0.04)$, vs HFFD-SMe25 $(p<0.0073)$, vs HFFD-SMe0.5 (p $<0.004), 3^{\text {rd }}$ min reperfusion: HFFD-C vs HFFD-SMe0.5 $(p<0.042)$.

the groups, although $+\mathrm{dP} / \mathrm{dt}$ values were moderately elevated in both SMe1EC2-treated groups (Fig. 3).

Ventricular arrhythmia (VA) appeared in 8 animals in the HFFD-C group, 4 cases of VA were observed in the HFFD-SMe25 group, while 5 animals had VA in the HFFD-A group, and 7 in the HFFD-C and HFFD-SMe0.5 group, respectively (Tab. 3).

Sustained ventricular fibrillation (SVF) was recorded in 4 animals in the control group, while 3 animals fibrillated in the HFFD-SMe25 group, 3 animals developed SVF in the HFFD-A group and 5 animals developed SVT in the HFFD-SMe 0.5 group.
Sustained ventricular tachycardia (SVT) was observed in 2 animals in the HFFD-C and HFFD-SMe0.5 groups, while 1 animal developed SVT in each of the HFFD-SMe25 and HFFD-A groups.

Ventricular premature beats (VPB) were as follows: altogether $1,229(123 \pm 30.6) \mathrm{VPB}$ were recorded in the HFFD-C group, 1,674

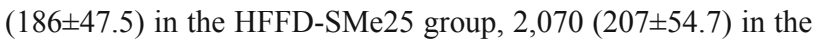
HFFD-SMe0.5 group and 2,308 (256 \pm 53.7$)$ VPB were recorded in the HFFD-A group.

SVF was induced in all the animals from the HFFD-C (with a mean of $25 \pm 4.6 \mathrm{~mA}$ ) and HFFD-A group (with a mean of 
Tab. 3. Occurrence of ventricular arrhythmia in animals among the groups.

\begin{tabular}{|c|c|c|c|c|}
\hline & HFFD-C & HFFD-A & HFFD-SMe25 & HFFD-SMe 0.5 \\
\hline Sustained ventricular fibrillation & 4 & 3 & 3 & 5 \\
\hline Sustained ventricular tachycardia & 2 & 1 & 1 & 2 \\
\hline Total cases of sustained ventricular arrhythmias & 6 & 4 & 4 & 7 \\
\hline Total arrhythmia cases* & 8 & 5 & 4 & 7 \\
\hline
\end{tabular}

*sustained VF and VT together with transient (short) VF or VT cases.

$27 \pm 4.0 \mathrm{~mA}$ ). Two cases in the HFFD-SMe25 group and one case in the HFFD-SMe0.5 group were without SVF. Mean dosage for the induction of SVF for the HFFD-SMe25 group was $24 \pm 4.0 \mathrm{~mA}$, while only $21 \pm 2.1 \mathrm{~mA}$ were sufficient for SVF induction for the HFFD-SMe 0.5 group.

The difference in time to sinus rhythm recovery after 2 minute SVF following the stop flow was not significant among the groups. Means of $97 \pm 32.0 \mathrm{~s}$ were recorded in the HFFD-C group, $92 \pm 48.0 \mathrm{~s}$ in the HFFD-SMe25 group, while $116 \pm 22.0 \mathrm{~s}$ and $121 \pm 38.0 \mathrm{~s}$ were recorded for the HFFD-A and HFFD-SMe0.5 groups, respectively.

\section{Discussion}

All the HFFD rats in this experiment developed metabolic syndrome (for details see 27). Compared to healthy Wistar rats, the animals had increased levels of total cholesterol, LDL cholesterol and triacylglycerols, while the levels of HDL cholesterol were decreased. Beside dyslipidemia, HTG rats fed with high-fat diet had increased blood pressure (28), elevated glucose levels and higher scores in the glucose tolerance test. On the other hand, the rats were not obese. The originally designed model to simulate hypertriacylglycerolemia was adapted by the means of diet change to give rise to other metabolic abnormalities and establish the metabolic syndrome. Both drugs, atorvastatin and SMe1EC2, produced cardio-tonic effect. Beside the elevation of LVDP, the drugs in all treatments positively influenced $-\mathrm{dP} / \mathrm{dt}$ and $+\mathrm{dP} / \mathrm{dt}$, while SMe1EC2 in lower dosage (HFFD-SMe0.5 group) had the most pronounced effect. The drugs failed to restore the baseline values of the heart physiology to output values (Tab. 1). The HFFD$\mathrm{SMe} 0.5$ group succeeded to establish the highest LVDP among the groups, namely with significantly higher values than those in the HFFD-C group. Both dosages of SMe1EC2 positively influenced $-\mathrm{dP} / \mathrm{dt}$ values after global ischemia.

As proposed in our hypotheses, the rats with metabolic syndrome were found to have increased chances of malignant arrhythmia occurrence (29) and untreated animals in this experiment were most susceptible to arrhythmia (the HFFD-C group). HFFD-A and HFFD-SMe25 groups had reduced numbers of malignant arrhythmia records, while the lower dosage of the experimental SMe1EC2 had no pronounced effect. Only 4 animals developed ventricular arrhythmia in the HFFD-SMe25 group in comparison to 8 animals in the HFFD-C group, while 5 animals developed ventricular arrhytmia in the HFFD-A group. Analysis and comparison of the total duration time of arrhythmia and the mean time of these arrhythmic episodes did not yield statistically significant differences among the groups. However the total and mean time of VT was lower in all the treatments in comparison to HFFD-C, while the total and the mean count of extrasystoles was higher in all treatments. The arrhythmic threshold in the cardio-stimulation experiment did not give statistically significant differences, although the threshold in atorvastatin group was slightly higher than in other groups. The mean time to sinus rhythm establishment after the stopped flow in fibrillating hearts was not significantly improved by any treatment. Atorvastatin produced effects comparable with SMe1EC2 in the same dosage. It reduced the total numbers of cases of sustained arrhythmia and arrhythmia in the given experiment and produced cardio-protective effects, as in previous research $(23,26)$.

Similarly to other statins, atorvastatin is thought to have many beneficial pleiotropic effects $(22,30)$. It also has been found to protect against cardiovascular events and reduce morbidity (31), act as anti-inflammatory agent in higher concentrations in subjects with metabolic syndrome (32) and have antioxidative effects (33). Acute atorvastatin treatment protected the heart against ischemiareperfusion injury following myocardial infarction in rats (34). In another experimental setting, atorvastatin was found to activate many pro-survival signalling pathways, which resulted in decreased infarction size and morbidity (35). As a result of these actions, preoperative administration of atorvastatin one week prior the coronary artery bypass grafting followed by postoperative atorvastatin treatment significantly decreased the incidence of atrial fibrillation (36). It may also be beneficial in diabetes mellitus treatment by reducing oxidative and inflammatory negative effects (37).

Anti-inflammatory and anti-oxidative effects with high free radicals scavenging activity is also known for $\operatorname{SMe1EC2}(38,39)$. Both atorvastatin and SMe1EC2 can thus protect the heart from excessive oxidative damage following ischemia/reperfusion injury. SMe1EC2 is thought to have many effects and could be used as a universal drug to partially treat all the metabolic syndrome symptoms (40) and affect arrhythmia development as previously reported (25), where decrease in arrhythmia occurrence was observed after direct perfusion with SMe1EC2 at a dose of $1 \times 10^{-5}$ M 10 at onset of ischemia and during reperfusion.

Both atorvastatin and SMe1EC2 exerted cardio protective effects $(22,26,31)$, established most probably by a complex action on numerous mechanisms affecting cell survival, signalling, oxidative and energy metabolism. In addition to lowering high cholesterol levels, atorvastatin treatment can protect patients suffering from metabolic syndrome, impaired lipid metabolism, and established cardiovascular disease from the occurrence of malignant life-threatening arrhythmia (23). SMe1EC2 showed cardio protective effects comparable with atorvastatin, and when considering also its other effects, it could be a beneficial drug for patients suffering from metabolic syndrome and cardiovascular disease in the future. 


\section{Learning points}

Similarly to other statins, atorvastatin has many pleiotropic actions including anti-arrhythmic and cardio-protective effects. SMe1EC2 pyridoindole derivative is a potent drug with antiarrhythmic effects as well as effects positively influencing the heart function.

\section{References}

1. Lusis JA. Atherosclerosis. Nature 2000; 407: 233-241.

2. Laufs U, Bohm M, Weingartner O, Werner C, Custodis F, Poss J. Cardiovascular disease and dyslipidemia: beyond LDL. Curr Pharm Design 2011; 17: 861-870.

3. Grundy SM. Metabolic syndrome: connecting and reconciling cardiovascular and diabetes worlds. J Am Coll Cardiol 2006; 47: 1093-1100.

4. Alberti KGMM, Eckel RH, Grundy SM et al. Harmonizing the metabolic syndrome. A joint interim statement of the International Diabetes Federation Task Force on Epidemiology and Prevention; National Heart, Lung and Blood Institute; American Heart Association; World Heart Federation; International Atherosclerosis Society; and International Association for the Study of Obesity. Circulation 2009; 120 : $1640-1645$.

5. Warburton DER, Nicol CW, Bredin SSD. Health benefits of physical activity: the evidence. CMAJ 2006; 147: 801-809.

6. Ahmed MH, Blaha JM, Nasir K, Rivera JJ, Blumenthal SR. Effects of physical activity on cardiovascular disease. Am J Cardiol 2012; 109: 288-295.

7. Nichols M, Townsend N, Luengo-Fernandez R, Leal J, Gray A, Scarborough P, Rayner M (Eds.). European cardiovascular disease statistics 2012. Brussels, Sophia Antipolis: European Heart Network, European Society of Cardiology, 2012: 1-125.

8. de Fatima Marinho de Souza M., Gawriszewski VP, Orduňez P, Sanhueza A, Espinal MA. Cardiovascular disease mortality in the Americas: current trends and disparities. Heart 2012; 98: 1207-1212.

9. Mozaffarian D, Benjamin EJ, Go SA et al. Heart disease and stroke statistics - 2016 update. A report from the American Heart Association. Circulation 2016; 133: e38-e360.

10. Campbell FWR, Murray A, Julian GD. Ventricular arrhythmias in first 12 hours of acute myocardial infarction. Natural history study. Brit Heart J 1981; 46: 351-357.

11. O'Doherty M, Tailer ID, Quinn E, Vincent R, Chamberlain AD. Five hundred patients with myocardial infarction monitored within one hour of symptoms. Brit Med J 1983; 286: 1405-1408.

12. Bayés de Luna A, Coumel P, Leclercq JF. Ambulatory sudden cardiac death: Mechanisms of production of fatal arrhythmia on the basis of data from 157 cases. Am Hearth J 1989; 117: 151-159.

13. Aguilar M, Bhuket T, Torres S, Liu B, Wong RJ. Prevalence of the Metabolic Syndrome in the United States, 2003-2012. JAMA 2015; 313: 1973-1974.

14. Cameron AJ, Shaw JE, Zimmet PZ. The metabolic syndrome: prevalence in worldwide population. Endocrin Metab Clin 2004; 33: 351-375.

15. Kaur J. A comprehensive review on metabolic syndrome. Cardiol Res Pract 2014; 2014: 973162.
16. Toth PP, Potter D, Ming EE. Prevalence of lipid abnormalities in the United States: the national health and nutrition examination survey 2003-2006. J Clin Lipidol 2012; 6: 325-330.

17. Gu D, Gupta A, Muntner P, Hu S et al. Prevalence of cardiovascular disease risk factor clustering among the adult population of China: results from the International Collaborative Study of Cardiovascular disease in Asia (InterAsia). Circulation 2005; 112: 658-665.

18. Scheidt-Nave C, Du Y, Knopf H et al. Prevalence of dyslipidemia among adults in Germany. Results of the German Health Interview and Examination Survey for Adults (DEGS1). Bundesgesundheitsbl 2013; 56: 661-667.

19. Smith SC Jr., Allen J, Blair SN et al. AHA/ACC guidelines for secondary prevention for patients with coronary and other atherosclerotic vascular disease: 2006 update: endorsed by the National Heart, Lung, and Blood Institute. Circulation 2006; 113: 2363-2372.

20. Huang PL. A comprehensive definition for metabolic syndrome. Dis Model Mech 2009; 2: 231-237.

21. Nissen SE. High-dose statins in acute coronary syndromes: not just lipid levels. JAMA 2004; 292: 1365-1367.

22. Robinson JG, Smith B, Maheshwari N, Schrott H. Pleiotropic effects of statins: benefit beyond cholesterol reduction? J Am Coll Cardiol 2005; 46: 1855-1862.

23. Benova T, Knezl V, Viczenczova C, Radosinska, Tribulova N. Acute anti-fibrillating and defibrillating potential of atorvastatin, melatonin, eicosapentaenoic acid and decosahexaenoic acid demonstrated in isolated heart model. J Physiol Pharmacol 2015; 66: 83-89.

24. Sola S, Mir MQS, Khan BV, Lerakis S, Tandon N. Atorvastatin improves left ventricular systolic function and serum markers of inflammation in noonischemic heart failure. J Am Coll Cardiol 2006; 47: 332-337.

25. Broskova Z, Knezl V. Protective effect of novel pyridoindole derivatives on ischemia/reperfusion injury of the isolated rat heart. Pharmacol Rep 2011; 63: 967-974.

26. Knezl V, Sotníková R, Brnoliaková Z, Stankovičová T, Bauer V,

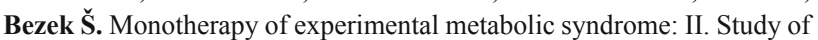
cardiovascular effects. Interdiscip Toxicol 2017; 10: 86-92.

27. Micháliková D, Tyukos Kaprinay B, Lipták B et al. Effect of highfat-fructose diet on synaptic plasticity in hippocampus and lipid profile of blood serum of rat: pharmacological possibilities of affecting risk factors. Eur Pharm J 2018; in press.

28. Roots CJ, Quax PHA, Jukema JW. Cardiovascular metabolic syndrome: mediators involved in the pathophysiology from obesity to coronary heart disease. Biomark Med 2012; 6: 35-52.

29. Lipták B, Kaprinay B, Gáspárová Z. A-rat friendly modification of the non-invasive taill cuff to record blood pressure. Lab Animal 2017; 46: $251-253$.

30. Lipták B, Knezl V, Gáspárová Z. Metabolic disturbances induce malignant heart arrhythmias in rats. Bratisl Med J 2017; 118: 539-543.

31. Bonnet J, McPherson R, Tedgui A, Simoneau D, Nozza A, Martineau P, Davignon J. Comparative effects of 10 -mg versus $80-\mathrm{mg}$ Atorvastatin on high-sensitivity $\mathrm{C}$-reactive protein in patients with stable coronary artery disease: results of the CAP (Comparative Atorvastatin Pleiotropis effects) study. Clinical Terapeutiscs 2008; 30: 2298-3213.

32. Calabrò $\mathbf{P}$, Yeh $\mathbf{E}$. The pleiotropic effects of statins. Curr Opin Cardiol 2005; 20: 541-546. 


\section{0-206}

33. Singh U, Devaraj S, Jialal I, Siegel D. Comparison effect of Atorvastatin (10 versus $80 \mathrm{mg}$ ) on biomarkers of inflammation and oxidative stress in subjects with metabolic syndrome. Am J Cardiol 2008; 102: 321-325.

34. Sugiyama M, Ohashhi M, Takese H, Sato K, Ueda R, Dohi Y. Effects of atorvastatin on inflammation and oxidative stress. Heart Vessels 2005; 20: 133-136.

35. Mensah K, Mocanu MM, Yellon DM. Failure to protect the myocardium against ischemia/reperfusion injury after chronic atorvastatin treatment is recaptured by acute atorvastatin treatment. J Am Coll Cardiol 2005; 45: 1287-1291.

36. Efthymiou Ch, Mocanu M, Yellon D. Atorvastatin and myocardial reperfusion injury: new pleiotropic effect impacting multiple prosurvival signalling. J Cardiovasc Pharm 2005; 45: 247-252.

37. Sun Y, Ji Q, Mei Y et al. Role of preoperative atorvastatin administration in protection against postoperative atrial fibrillation following conventional coronary artery bypass grafting. Int Heart J 2011; 52: 7-11.
38. Riad A, Du J, Stiehl S et al. Low-dose treatment with atorvastatin leads to anti-oxidative and anti-inflammatory effects in diabetes mellitus. Eur J Pharmacol 2007; 569: 204-211.

39. Stefek M, Milackova I, Juskova-Karasova M, Snirc V. Antioxidant ection of the hexadydropiridoindole SMe1EC2 in the cellular system of isolated red blood cells in vitro. Redox Rep 2013; 18: 71-75.

40. Rackova L, Snirc V, Majekova M, Majek P, Stefek M. Free radical scavenging and antioxidant activities of substituted hexahydropyridoindoles. Quantitative structure-activity relationships. J M Chem 2006; 49: 2543-2548.

41. Bezek Š, Brnoliaková Z, Sotníková R, Knezl V, Paulovičová E, Navarová J, Bauer V. Monotherapy of experimental metabolic syndrome: I. Efficacy and safety. Interdiscip Toxicol 2017; 10: 81-85.

Received December 10, 2018. Accepted January 25, 2019. 